\title{
Assessment of Modified Rice Husks for Removal of Aniline in Batch Adsorption Process: Optimization and Isotherm Study
}

\author{
Ihsan Habib Dakhil ${ }^{1 *}$, Ghazi Faisal Naser ${ }^{1}$, Ahmed Hassan Ali $^{3}$ \\ 1 Department of Chemical Engineering Department, College of Engineering, Al-Muthanna University, Iraq \\ * Corresponding author's e-mail: em2ihsan@mu.edu.iq
}

\begin{abstract}
The present work is aimed at investigating the capability of chemically modified rice husks (MRH) for the reduction of aniline ions from industrial wastewater. The experiments have been conducted to examine the influence of four operating parameters in the batch adsorption technique. The effect of initial concentrations of aniline (10-100) $\mathrm{mg} \cdot \mathrm{L}^{-1}, \mathrm{MRH}$ dose (0.1-1) g/100 $\mathrm{ml}, \mathrm{pH}$ (3-9), and contact time (10-90) $\mathrm{min}$ has been studied. The selected range of operating factors was designed using the response surface method to establish a mathematical model that describes the adsorption process. The optimum parameters were $25 \mathrm{mg} \cdot \mathrm{L}^{-1}$ initial concentration of aniline, $0.68 \mathrm{~g}$ MRH dose, $6.6 \mathrm{pH}$, and 70 min contact time. The point of zero charge was found equal to 6.8. The maximum removal efficiency of $84.97 \%$ was found under optimum conditions. The consistency of the mathematical model has been examined and the equilibrium results confirmed with the standard adsorption isotherm models, Langmuir and Freundlich, with a high correlation coefficient.
\end{abstract}

Keywords: adsorption, aniline, modified rice husk, optimization, pzc.

\section{INTRODUCTION}

Aniline may be considered as a highly toxic organic compound since it has a phenolic group in its chemical structure and has a harmful effect even at low concentrations. It is used as raw material in manufacturing various chemical materials such as pharmaceutical products, plastics, dyes of textile, paints, and rubber (Liu et al. 2015, Thakur and Qanungo 2020).

The removal of toxic organic compounds from contaminated wastewater has become one of the matters that receive very wide attention by many researchers, due to the danger of emitting these pollutants into the environment and their direct impact on living organisms. Traditionally, there are several ways to remove or reduce the excreted concentrations of toxic pollutants, including physical, chemical, and biological methods. Previous studies focused on several technologies and methods of treating contaminated wastewater such as photocatalytic (Ali and Dakhil 2012, Taher et al. 2018), advance oxidation (Ali 2017, Ahmed et al. 2018), biological treatment (Jiang et al. 2016), electrochemical oxidation (Ferreira et al. 2015), composite membranes (Shao et al. 2013), chemical coagulation (Ahmadi et al. 2017).

In recent decades, the adsorption method has been proven as an excellent way of removing many kinds of pollutants from wastewater. Since the successful method for any wastewater treatment is dependent upon its cost, a large number of researchers have been interested in finding the materials that use adsorbent materials in the adsorption process, being eco-friendly at the same time. According to literature studies in recent decades, the researchers' interest focused on the finding of cheap adsorbents that may be used as adsorbents for wastewater treatment and to study the effectiveness of these materials to remove pollutants such as removal of methyl orange dye using different agriculture wastes (Dakhil 2016a, 2020). In addition, modern studies focused on preparing activated carbon from agricultural wastes as eco-friendly adsorbents, such as the production of activated carbon prepared from date palm fibers (Dakhil and Ali 2021, Melliti et al. 2021). 
The importance of this work involves highlighting the chemical modification of agricultural wastes (i.e. rice husks) and examining the ability of MRH to remove aniline ions from contaminated water, as well as optimizing the operating factors under batch adsorption technique. After that, the results obtained from the laboratory experiments were compared with the Langmuir and Freundlich isotherm adsorption models.

\section{MATERIALS AND METHODS}

\section{Preparing of Adsorbent}

Rice husks were collected from agriculture fields. They was washed several times in tap water to remove any dust and then rinsed with distilled water. The husks were dried under the sun for 48 hours; after that, the rice husks were dried in an electric oven at $75^{\circ} \mathrm{C}$ overnight, then they were cut and sieved to the size of $1-2 \mathrm{~mm}$ using a mesh sieve (Besmak sieve). The chemical activation of adsorbent follows the same procedure that was presented by Dakhil et al. (2021) which includes two steps; carbonization and impregnation. The first step represented carbonization of rice husk that happened by passing nitrogen gas in an oven at $800^{\circ} \mathrm{C}$ for two hours. The second step was impregnation of the carbonized rice husk with a solution of potassium hydroxide $(\mathrm{KOH})$ using a ratio of $(2: 1)(\mathrm{KOH} / \mathrm{RH})$. The physiochemical characterizations of MRH are presented in Table 1.

\section{Adsorbate}

The stock aniline solution was prepared by dissolving an accurate amount of $(1 \mathrm{~g})$ aniline $\left(\mathrm{C}_{6} \mathrm{H}_{5} \mathrm{NH}_{2}\right)$ (supplied by Merck, Germany) in 1 liter of distillate water to produce a stock solution of $\left(1000 \mathrm{mg} \cdot \mathrm{L}^{-1}\right)$. The desired initial concentration at each experiment was prepared using the

Table 1. Physiochemical characterization of MRH

\begin{tabular}{|l|c|}
\hline \multicolumn{1}{|c|}{ Property } & Value \\
\hline Surface area $\left(\mathrm{m}^{2} \cdot \mathrm{g}^{-1}\right)$ & 79.3 \\
\hline Point of zero charge & 6.8 \\
\hline Bulk density $\left({\left.\mathrm{g} \cdot \mathrm{m}^{-3}\right)}^{3}\right)$ & 5.7 \\
\hline Pore volume $\left(\mathrm{cm}^{3} \cdot \mathrm{g}\right)$ & 0.76 \\
\hline Moisture content $(\%)$ & 2.8 \\
\hline Ash content $(\%)$ & 23.4 \\
\hline
\end{tabular}

dilution equation. The $\mathrm{pH}$ for experimental runs was measured using a digital $\mathrm{pH}$ meter and it was adjusted by adding drops of $0.01 \mathrm{~N}$ of $\mathrm{NaOH}$ (purity $98 \%$ ) and $0.01 \mathrm{~N}$ of $\mathrm{HCl}$ (purity $36 \%$ ).

\section{Point of Zero Charge}

The solid addition method was used to determine the point of zero charge (Srivastava et al. 2006). A series of $100 \mathrm{ml}$ conical flasks filled with $45 \mathrm{ml}$ of $0.01 \mathrm{M} \mathrm{KNO}_{3}$, after which the $\mathrm{pH}$ of the solution was adjusted by adding drops of $0.01 \mathrm{~N}$ $\mathrm{HCl}$ or $0.01 \mathrm{~N} \mathrm{NaOH}$ in the range (3-9), then the volume was topped up to $50 \mathrm{ml}$ by adding $\mathrm{KNO}_{3}$. The initial $\mathrm{pH}\left(\mathrm{pH}_{0}\right)$ was measured using a digital $\mathrm{pH}$ meter. $\mathrm{MRH}$ in the amount of $1 \mathrm{gm}$ was added to each flask and placed on a magnetic stirrer for 48 hours at speed 120 r.p.m. After that, the solution was filtered and measure $\mathrm{pH}$ which was represented $\left(\mathrm{pH}_{\mathrm{f}}\right)$. The difference between the initial readings $\left(\mathrm{pH}_{0}\right)$ and final reading $\left(\mathrm{pH}_{\mathrm{f}}\right)$ is represented $(\Delta \mathrm{pH})$. The $\Delta \mathrm{pH}$ values were plotted against $\mathrm{pH}_{0}$. The point of intersection of the curve with the zero on the y-axis represents $\left(\mathrm{pH}_{\mathrm{ZPC}}\right)$.

\section{Batch Adsorption Process}

In order to study the effect of operating parameters on the adsorption process, the experiments were designed using the response surface method with two affecting levels. The range of operating parameters was initial aniline concentration (10-100) mg/l, MRH dose (0.1-1) g, pH (3-9), and mixing time (10-90) $\mathrm{min}$. A $100 \mathrm{ml}$ of simulated wastewater with aniline ions were poured into a conical flask that was mixed using a magnetic shaker with constant stirrer mixing at 150 r.p.m. The experiments were conducted under the constant temperature at $30 \pm 2^{\circ} \mathrm{C}$. At end of each experiment, a $3 \mathrm{ml}$ sample was withdrawn using a graduated syringe to measure the equilibrium concentration. The initial and equilibrium concentration of aniline for each experiment has measured by a UV-Visible spectrophotometer (Shimadzu Inc., Japan) at wavelength $525 \mathrm{~nm}$. The removal efficiency and amount adsorption of aniline at end of each experiment were calculated by the equation (1) and equation (2):

$$
\text { Removal Efficiency }=\frac{\left(C_{o}-C_{e}\right)}{C_{o}} \times 100
$$




$$
q_{e}=\frac{V\left(\mathrm{C}_{\mathrm{o}}-\mathrm{C}_{\mathrm{e}}\right)}{m}
$$

The initial and final concentrations of aniline were represented by the symbols of $\mathrm{C}_{\mathrm{o}}$ and $\mathrm{C}_{\mathrm{e}}$, respectively; $\mathrm{m}$ represents the amount of $\mathrm{MRH}$ in the unit of a gram and the volume of simulated wastewater in the unit of liter was represented by V.

\section{EXPERIMENTAL DESIGN}

The batch adsorption experiments were designed using central composite design CCD with the response surface method. The Minitab version 19 was used to analyze the sequence of experimental runs with 2 levels of factor changing. The operating factors are represented by initial aniline concentration (A), MRH dose (B), $\mathrm{pH}(\mathrm{C})$, and mixing time (D). The experimental ranges and levels of the operating factors were listed in Table 2.

According to the CCD, the number of experiment runs was 30 , which required creating a mathematical model for describing the removal efficiency of aniline. The optimization of operating factors was analyzed to give maximum desirability. Table 3 shows the design of experimental runs of coded and real values of operating factors using the response surface method RSM.

\section{RESULTS AND DISCUSSION}

The experimental results were concerned to evaluate the impact of tested parameters on the aniline removal efficiency using MRH as an eco-friendly adsorbent, the batch adsorption experiments were designed to achieve a polynomial mathematical model to characterize the adsorption of aniline from its aqueous solutions. The equilibrium data were analyzed to optimize the results and to obtain maximum removal efficiency and adsorption capacity under optimum operating conditions.

\section{Statistical analysis and optimization}

The removal efficiency of aniline was studied with four independent variables. The initial concentration of aniline (A), MRH dose (B), $\mathrm{pH}(\mathrm{C})$, and mixing time (D). The experiments were designed using Box-Wilson design for the selected operating factors with thirty runs according to response surface methodology (RSM). The statistical design of experiments fitted to the quadratic mathematical model of real variables as shown in equation 3:

$\%$ Removal of Aniline $=44.1-0.100 \mathrm{~A}+$

$+37.1 \mathrm{~B}+7.49 \mathrm{C}+0.133 \mathrm{D}-0.00105 \mathrm{~A}^{2}-$

$-22.8 \mathrm{~B}^{2}-0.569 \mathrm{C}^{2}-0.00164 \mathrm{D}^{2}+$

$+0.062 \mathrm{AB}+0.0093 \mathrm{AC}+0.00069 \mathrm{AD}-$

$-1.30 \mathrm{BC}+0.014 \mathrm{BD}+0.0104 \mathrm{CD}$

According to statistical analysis using minitab version 19 , the correlation factor $\left(\mathrm{R}^{2}\right)$ for concluded mathematical model equal to (0.98), and the variance (S) equal to $(97.6 \%)$. ANOVA was performed to measure the acceptability of the mathematical model obtained from experimental results. Table 4 illustrates the fitting results of the mathematical model using ANOVA. From this table, the significant effect of each parameter and interacting with others was evaluated at a level of $95 \%$ confidence. The significant term was detected at a p-value of less than 0.05 . In addition, Figure 1 shows the graphical horizontal bars that measure the significance of each term in the mathematical model that is known as the Pareto chart.

The red vertical line in the Pareto chart represented the minimum value of significant influence magnitude of the $5 \%$ risk that is equal to 2.131. From ANOVA and Pareto chart, the significant terms were represented by the initial concentration of aniline (A), MRH dose (B), $\mathrm{pH}(\mathrm{C})$,

Table 2. Experimental range of operating factors

\begin{tabular}{|l|c|c|c|c|c|c|}
\hline \multicolumn{1}{|c|}{ Factor } & Variable & -2 & -1 & 0 & -2 \\
\hline Initial concentration & A & 10 & 32.5 & 55 & 77.5 & 100 \\
\hline MRH dosage & B & 0.1 & 0.325 & 0.55 & 0.775 & 1.0 \\
\hline $\mathrm{pH}$ & $\mathrm{C}$ & 3 & 4.5 & 6 & 7.5 & 9 \\
\hline Time & $\mathrm{D}$ & 10 & 30 & 50 & 70 \\
\hline
\end{tabular}


Table 3. The experimental design of RSM

\begin{tabular}{|c|c|c|c|c|c|c|c|c|c|}
\hline Run & $A$ & $B$ & $C$ & $\mathrm{D}$ & Conc. & Dose & $\mathrm{pH}$ & time & $\% R$ \\
\hline 3 & -1 & 1 & -1 & -1 & 32.5 & 0.775 & 4.5 & 30 & 80 \\
\hline 4 & 1 & 1 & -1 & -1 & 77.5 & 0.775 & 4.5 & 30 & 76 \\
\hline 5 & -1 & -1 & 1 & -1 & 32.5 & 0.325 & 7.5 & 30 & 80 \\
\hline 6 & 1 & -1 & 1 & -1 & 77.5 & 0.325 & 7.5 & 30 & 75 \\
\hline 7 & -1 & 1 & 1 & -1 & 32.5 & 0.775 & 7.5 & 30 & 83 \\
\hline 8 & 1 & 1 & 1 & -1 & 77.5 & 0.775 & 7.5 & 30 & 80 \\
\hline 9 & -1 & -1 & -1 & 1 & 32.5 & 0.325 & 4.5 & 70 & 78 \\
\hline 10 & 1 & -1 & -1 & 1 & 77.5 & 0.325 & 4.5 & 70 & 73 \\
\hline 11 & -1 & 1 & -1 & 1 & 32.5 & 0.775 & 4.5 & 70 & 83 \\
\hline 12 & 1 & 1 & -1 & 1 & 77.5 & 0.775 & 4.5 & 70 & 80 \\
\hline 13 & -1 & -1 & 1 & 1 & 32.5 & 0.325 & 7.5 & 70 & 83 \\
\hline 14 & 1 & -1 & 1 & 1 & 77.5 & 0.325 & 7.5 & 70 & 81 \\
\hline 15 & -1 & 1 & 1 & 1 & 32.5 & 0.775 & 7.5 & 70 & 87 \\
\hline 16 & 1 & 1 & 1 & 1 & 77.5 & 0.775 & 7.5 & 70 & 85 \\
\hline 17 & 0 & 0 & 0 & 0 & 55 & 0.55 & 6 & 50 & 83 \\
\hline 18 & 0 & 0 & 0 & 0 & 55 & 0.55 & 6 & 50 & 83 \\
\hline 19 & 0 & 0 & 0 & 0 & 55 & 0.55 & 6 & 50 & 83 \\
\hline 20 & 0 & 0 & 0 & 0 & 55 & 0.55 & 6 & 50 & 83 \\
\hline 21 & -2 & 0 & 0 & 0 & 10 & 0.55 & 6 & 50 & 83 \\
\hline 22 & 2 & 0 & 0 & 0 & 100 & 0.55 & 6 & 50 & 73 \\
\hline 23 & 0 & -2 & 0 & 0 & 55 & 0.1 & 6 & 50 & 74 \\
\hline 24 & 0 & 2 & 0 & 0 & 55 & 1 & 6 & 50 & 77 \\
\hline 25 & 0 & 0 & -2 & 0 & 55 & 0.55 & 3 & 50 & 76 \\
\hline 26 & 0 & 0 & 2 & 0 & 55 & 0.55 & 9 & 50 & 74 \\
\hline 27 & 0 & 0 & 0 & -2 & 55 & 0.55 & 6 & 10 & 76 \\
\hline 28 & 0 & 0 & 0 & 2 & 55 & 0.55 & 6 & 90 & 79 \\
\hline 29 & 0 & 0 & 0 & 0 & 55 & 0.55 & 6 & 50 & 80 \\
\hline 30 & 0 & 0 & 0 & 0 & 55 & 0.55 & 6 & 50 & 80 \\
\hline
\end{tabular}

Table 4. ANOVA for Aniline adsorption model

\begin{tabular}{|c|c|c|c|c|c|}
\hline Source & DF & Adj SS & Adj MS & F-Value & P-Value \\
\hline Model & 14 & 377.950 & 26.996 & 3.19 & 0.016 \\
\hline Linear & 4 & 292.500 & 73.125 & 8.65 & 0.001 \\
\hline$A$ & 1 & 100.042 & 100.042 & 11.84 & 0.004 \\
\hline B & 1 & 84.375 & 84.375 & 9.99 & 0.006 \\
\hline$C$ & 1 & 51.042 & 51.042 & 6.04 & 0.027 \\
\hline $\mathrm{D}$ & 1 & 57.042 & 57.042 & 6.75 & 0.020 \\
\hline$A^{2}$ & 1 & 7.741 & 7.741 & 0.92 & 0.354 \\
\hline$B^{2}$ & 1 & 36.670 & 36.670 & 4.34 & 0.055 \\
\hline$C^{2}$ & 1 & 45.027 & 45.027 & 5.33 & 0.036 \\
\hline $\mathrm{D}^{2}$ & 1 & 11.812 & 11.812 & 1.40 & 0.255 \\
\hline$A B$ & 1 & 1.562 & 1.562 & 0.18 & 0.673 \\
\hline$A C$ & 1 & 1.563 & 1.563 & 0.18 & 0.673 \\
\hline$A D$ & 1 & 1.562 & 1.562 & 0.18 & 0.673 \\
\hline$B C$ & 1 & 3.062 & 3.062 & 0.36 & 0.556 \\
\hline $\mathrm{BD}$ & 1 & 0.063 & 0.063 & 0.01 & 0.933 \\
\hline$C D$ & 1 & 1.563 & 1.563 & 0.18 & 0.673 \\
\hline Error & 15 & 126.750 & 8.450 & & \\
\hline
\end{tabular}




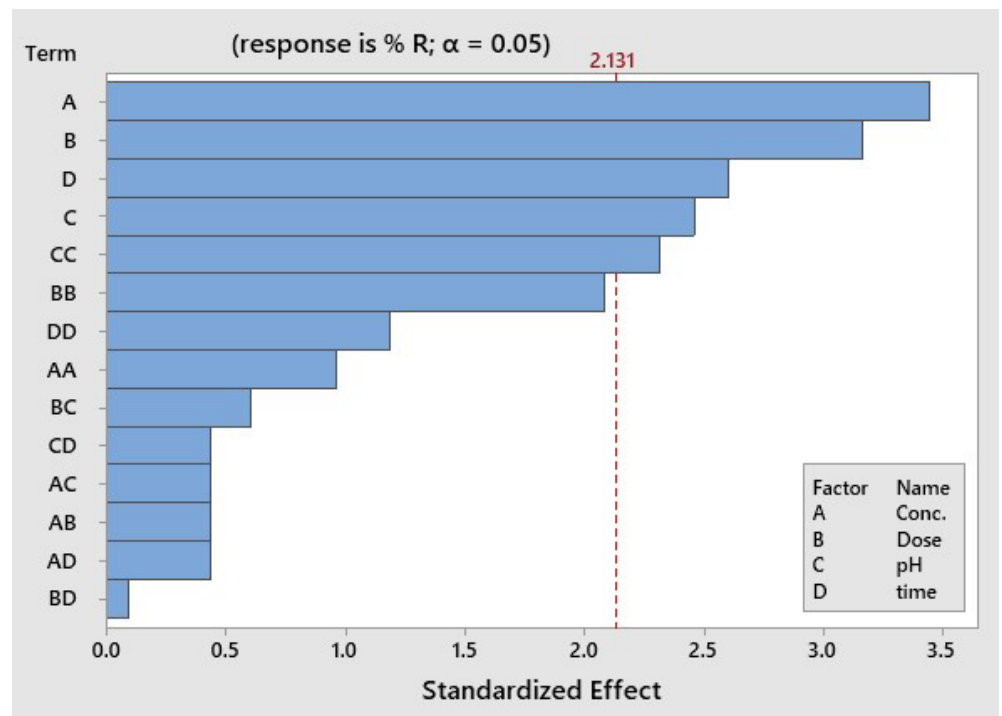

Figure 1. Standardized effect of Pareto chart

contact time (D), and square $\mathrm{pH}$ factor (CC). The other terms were insignificant.

In order to optimize the selected range of factors, the equilibrium results were analyzed to achieve the maximum desirable value of removal efficiency under optimum operating conditions. Figure 2 shows the shape of studied factors on the removal efficiency of aniline. According to RSM analysis, the optimum conditions were initial aniline concentration 25 of mg. $\mathrm{L}^{-1}$, MRH dose $0.68 \mathrm{~g}$, $\mathrm{pH}$ 6.6, and contact time $70 \mathrm{~min}$. Under these conditions, the maximum removal efficiency was $84.97 \%$. The duplicate of experiments with optimum conditions of four operating parameters has been performed to confirm the results.

Figure 3 illustrates the relationship between adsorption capacity and the initial concentration of aniline. From this figure, the maximum uptake under the optimum conditions of other factors was achieved at $11.63 \mathrm{mg} \cdot \mathrm{g}^{-1}$.

Figure 4 represented the relationship between $\Delta \mathrm{pH}$ on the y-axis and $\mathrm{pH}_{0}$ on the $\mathrm{x}$-axis. The intersection point of the curve with the zero point on the $y$-axis represented the point of zero charge $\left(\mathrm{pH}_{\mathrm{ZPC}}\right)$. The $\mathrm{pH}_{\mathrm{ZPC}}$ for the MRH was found equal to 6.8. The point of zero charge for the MRH $\left(\mathrm{pH}_{\mathrm{ZPC}}=6.8\right)$, this result is in agreement with the findings of Kolar and Jin (2019) and N'Diaye, Boudokhane (2019) which are equal to 6.1 and 6.8 , respectively. Thus, the MRH surface charge is positive at $\mathrm{pH}$ lower than $\mathrm{pH}_{\mathrm{ZPC}}$, whereas the surface charge is negative at $\mathrm{pH}$ greater than $\mathrm{pH}_{\mathrm{ZPC}}$.

\section{EFFECT OF OPERATING VARIABLES}

According to statistical analysis, the experimental results obtained will be discussed in this section through a graphical representation in a three-dimensional plotting of two operating variables with the constant of the other two factors under constant optimal conditions as shown in Figures (a) as well as by plotting the contour in Figures (b).

The most influential factor that affected the adsorption of aniline on MRH was the initial

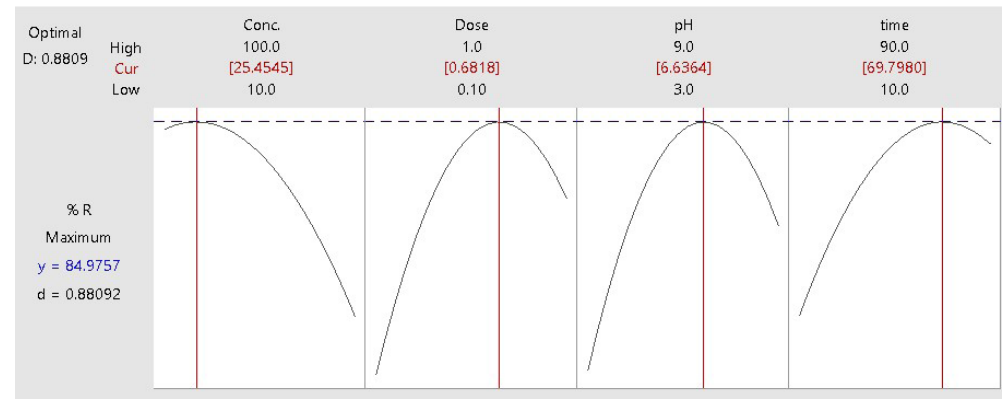

Figure 2. Optimization of operating factor on removal efficiency 


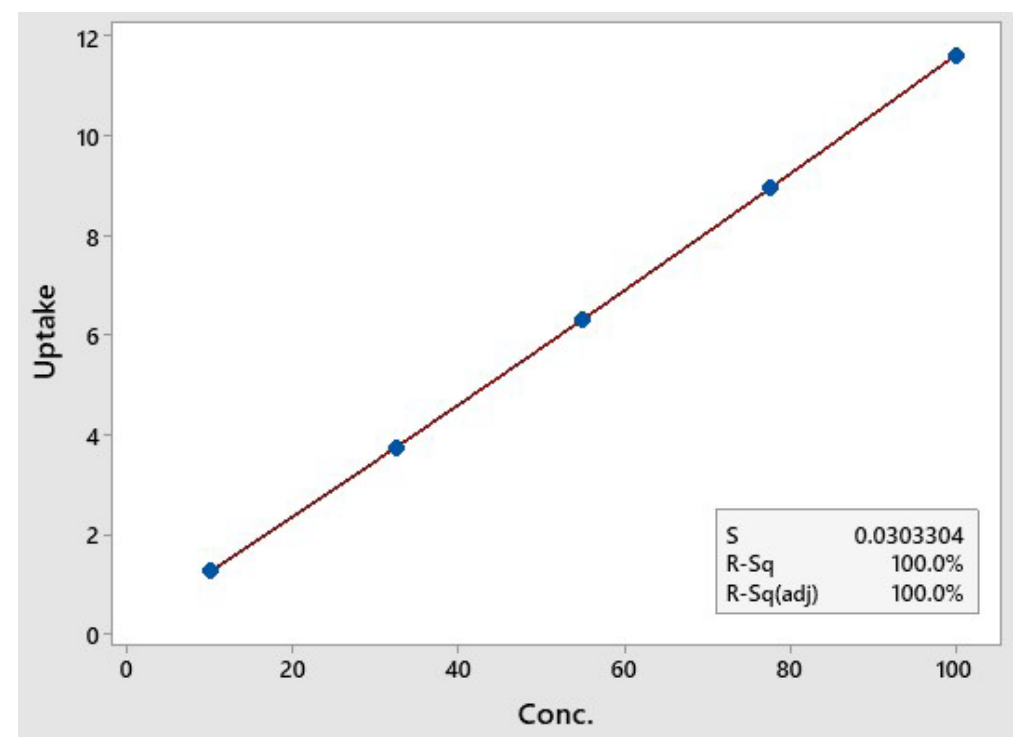

Figure 3. The uptake of aniline on MRH

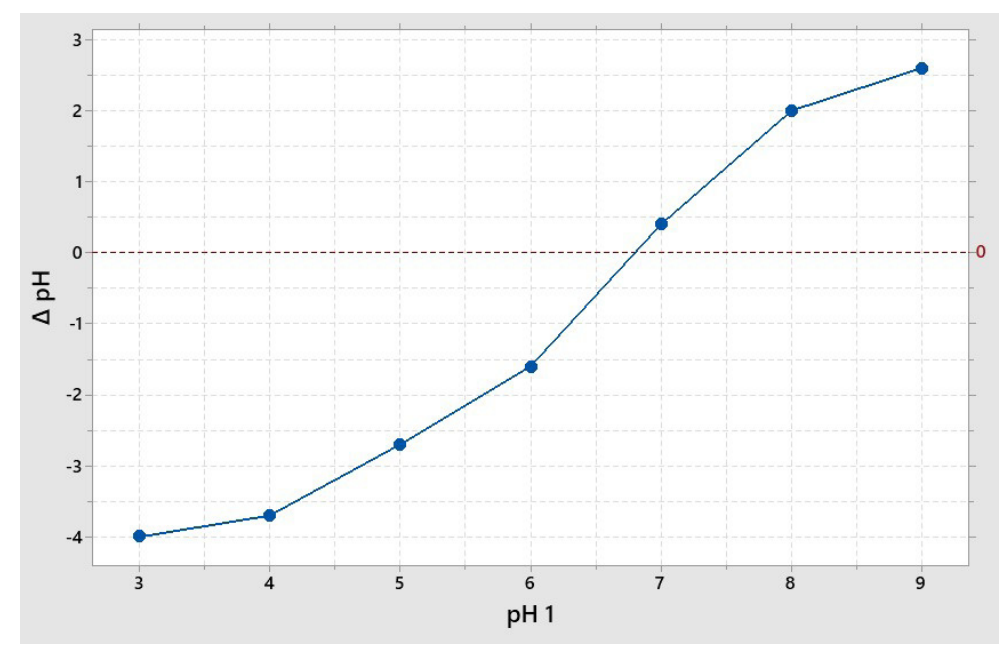

Figure 4. The point of zero charge

concentration of aniline. Figure 5 ( $\mathrm{a}$ and $\mathrm{b}$ ) illustrates the effect of the initial concentration of aniline against the MRH dose with the removal efficiency under constant optimum values of $\mathrm{pH}$ and contact time at 6.6 and $70 \mathrm{~min}$, respectively. The results show that the removal efficiency decreases with increasing of initial concentrations of aniline and increases along with the MRH dose till the optimum value of adsorbent dose $(0.68 \mathrm{~g})$. The increase of removal efficiency at the first period was due to the available vacant sites on the adsorbent dose. After optimum values, the curves of removal efficiency continue in straight lines due to saturation of vacant sites of adsorbent. This result or phenomenon coincides with the results of most researchers, such as adsorption on spent tea leaves (Dakhil 2013) and adsorption of pine sawdust (Zhou et al. 2014, Dakhil 2016b). The maximum removal efficiency has occurred at $25 \mathrm{mg} \cdot \mathrm{g}^{-1}$ of initial concentration and $0.68 \mathrm{~g}$ of MRH.

Figure $6(a$ and $b)$ represents the effect of initial concentrations of aniline versus $\mathrm{pH}$ with the removal efficiency at constant the other two factors, MRH dosage and contact time, at $0.68 \mathrm{~g}$ and $70 \mathrm{~min}$, respectively. Aniline is represented as weak base and has anion charge. The effect of $\mathrm{pH}$ on the adsorption of aniline depends mainly on the point of zero charge $\left(\mathrm{pH}_{\mathrm{ZPC}}\right)$ of $\mathrm{MRH}$. The zero point charge means that the charge of adsorbate (aniline) on the surface of the adsorbent (MRH) is zero. The calculated point of zero charge $\left(\mathrm{pH}_{\mathrm{ZPC}}\right)$ indicates that the surface charge of MRH is negative in a solution the $\mathrm{pH}$ of which is greater than 6.8 , conversely the surface charge is positive when $\mathrm{pH}$ is less than 6.8 . In the acidic medium, when $\mathrm{pH}<\mathrm{pH}_{\mathrm{ZPC}}$, the removal efficiency 
a)

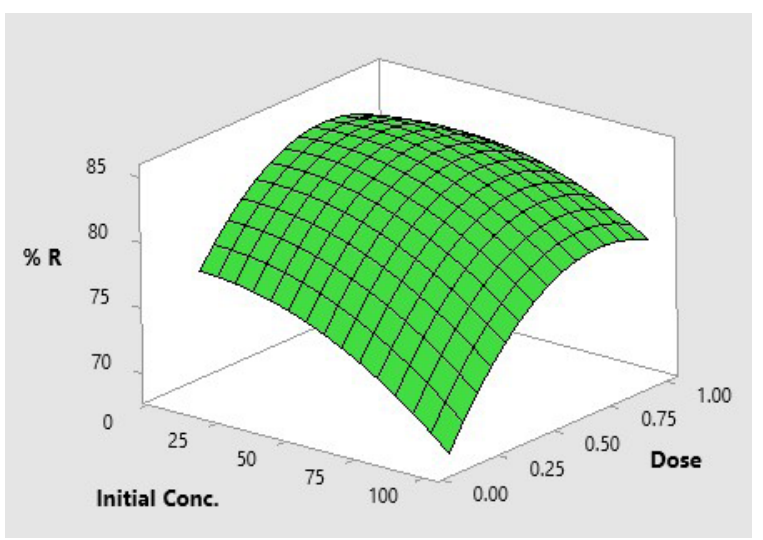

b)

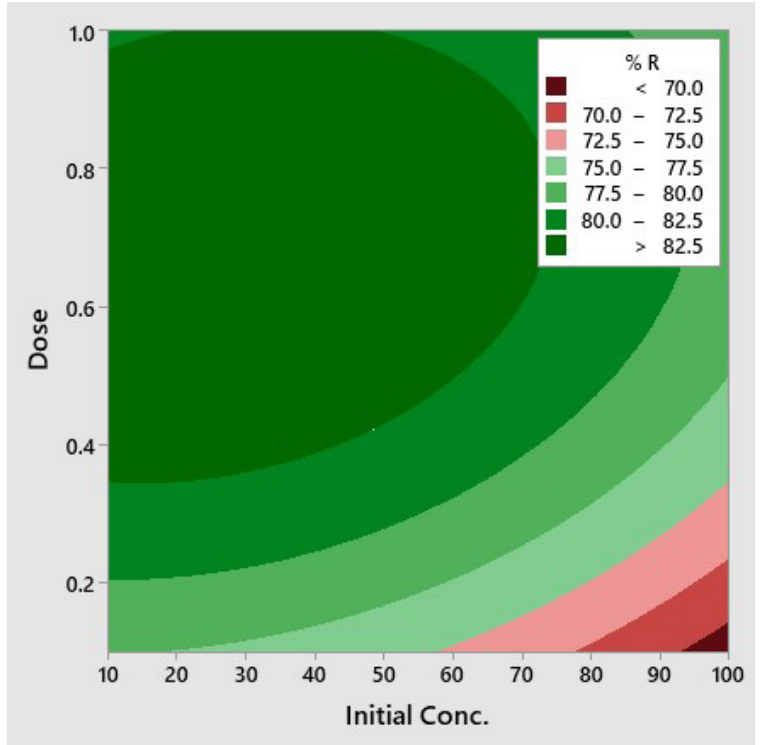

Figure 5. Effect of initial concentration vs. MRH dose

of aniline increases in the range of $\mathrm{pH}=3$ till the optimum value $\mathrm{pH}=6.6$. This result is due to the positive charge of the surface MRH that effectively adsorb the negative ions of aniline. On the other hand, when $\mathrm{pH}>\mathrm{pH}_{\mathrm{ZPC}}$, the removal efficiency decreases with the increasing $\mathrm{pH}$ value. This result is due to the formation of hydroxyl ions $\mathrm{OH}^{-}$which is competing with the negative charge of the MRH surface. These results are in agreement with almost all research findings, such as adsorption of aniline using modified pine sawdust (Zhou et al. 2017) and on activated carbon coated by chitosan (Liu et al. 2015).

a)

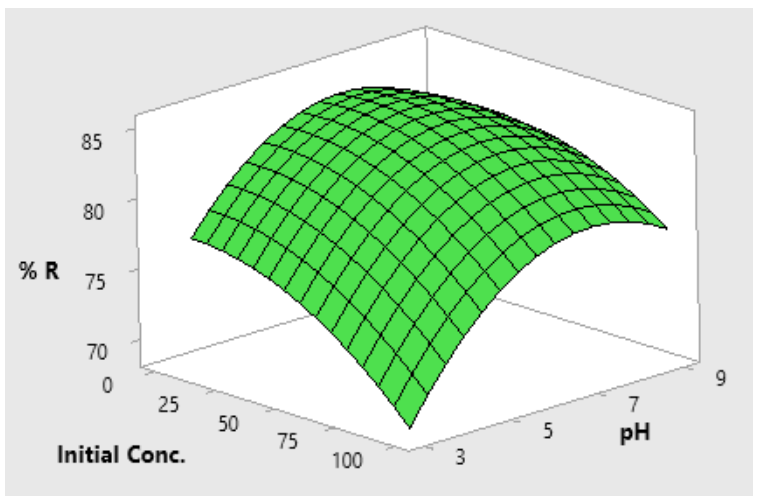

Figure 7 ( $a$ and $b$ ) shows the effect of the initial concentration of aniline against contact time concerning the removal efficiency at constant the two factors, MRH dose, and $\mathrm{pH}$ under the optimum condition of $0.68 \mathrm{~g}$ and 6.6 , respectively. The results showed that the removal efficiency of aniline increased rapidly in the first period with increasing contact time. The saturation point was occurred at $70 \mathrm{~min}$ by making a monolayer of aniline ions over the surface of the adsorbent. This result was in agreement with the finding of equilibrium contact time 60 min which was observed in the

b)

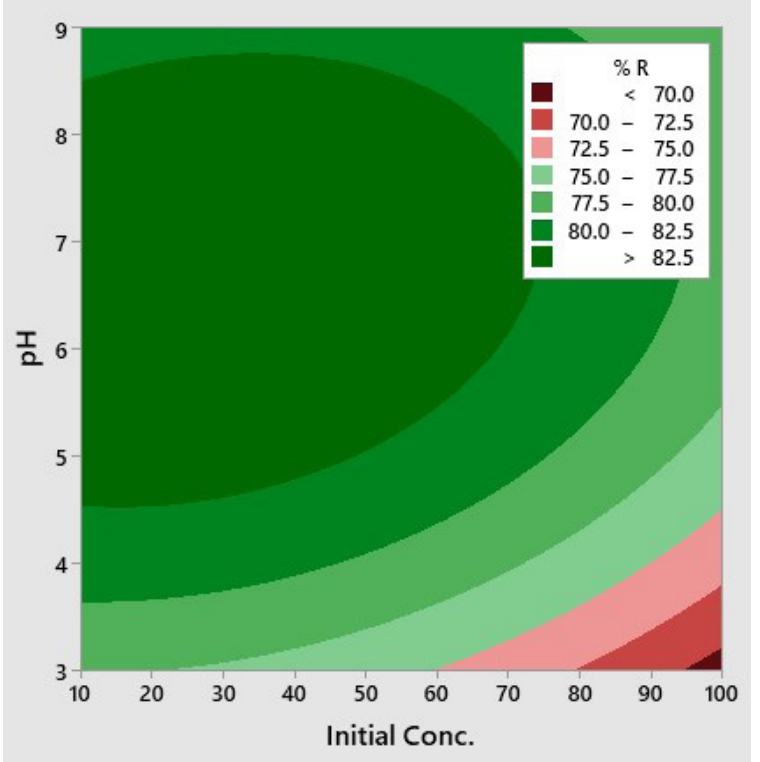

Figure 6. Effect of initial concentration vs. $\mathrm{pH}$ 
a)

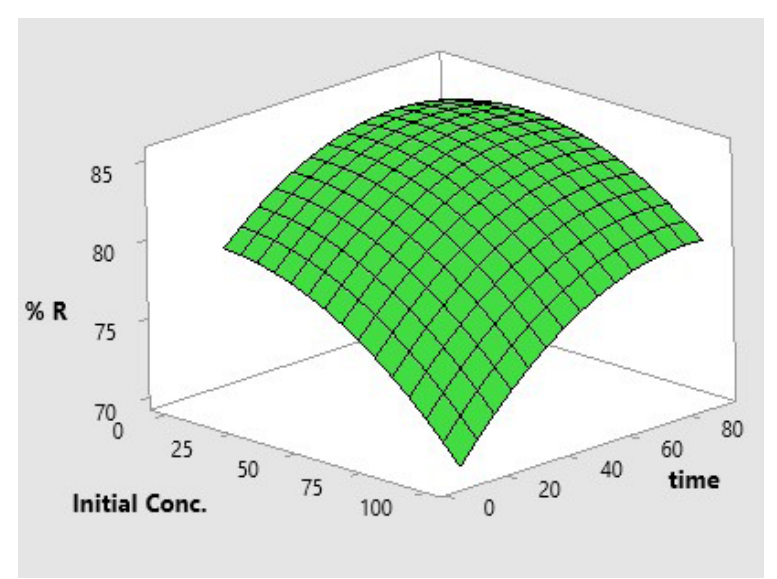

b)

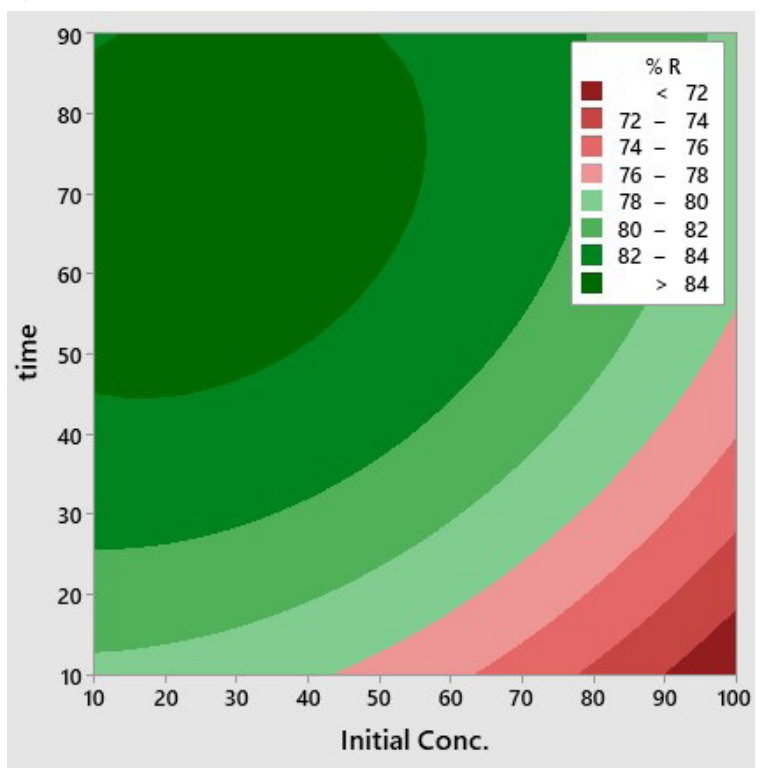

Figure 7. Effect of initial concentration vs. contact time

study adsorption of aniline on a nanocomposite of $\mathrm{Fe}_{3} \mathrm{O}_{4}$ /graphene (Chang et al. 2012) and in the study adsorption of aniline using Aloe Vera leaves waste (Khaniabadi et al. 2016).

In order to comprehensively assess the mutual effect between any two operating parameters, Figure 8 illustrates the combined effect of the interacting operating factors. The parallel curves mean no interaction between the factors and if the curves are non-parallel, there is interaction between the factors. The strong interaction depends on the large angle between the two curves. Figure 8 shows the interacting effect of four operating parameters on the removal efficiency of aniline. From this figure, it can be noticed that the initial concentration of aniline has well interacted with other factors in the ranges of (0.5-1) g MRH dose, (6-9) $\mathrm{pH}$, and (50-90) min contact time.

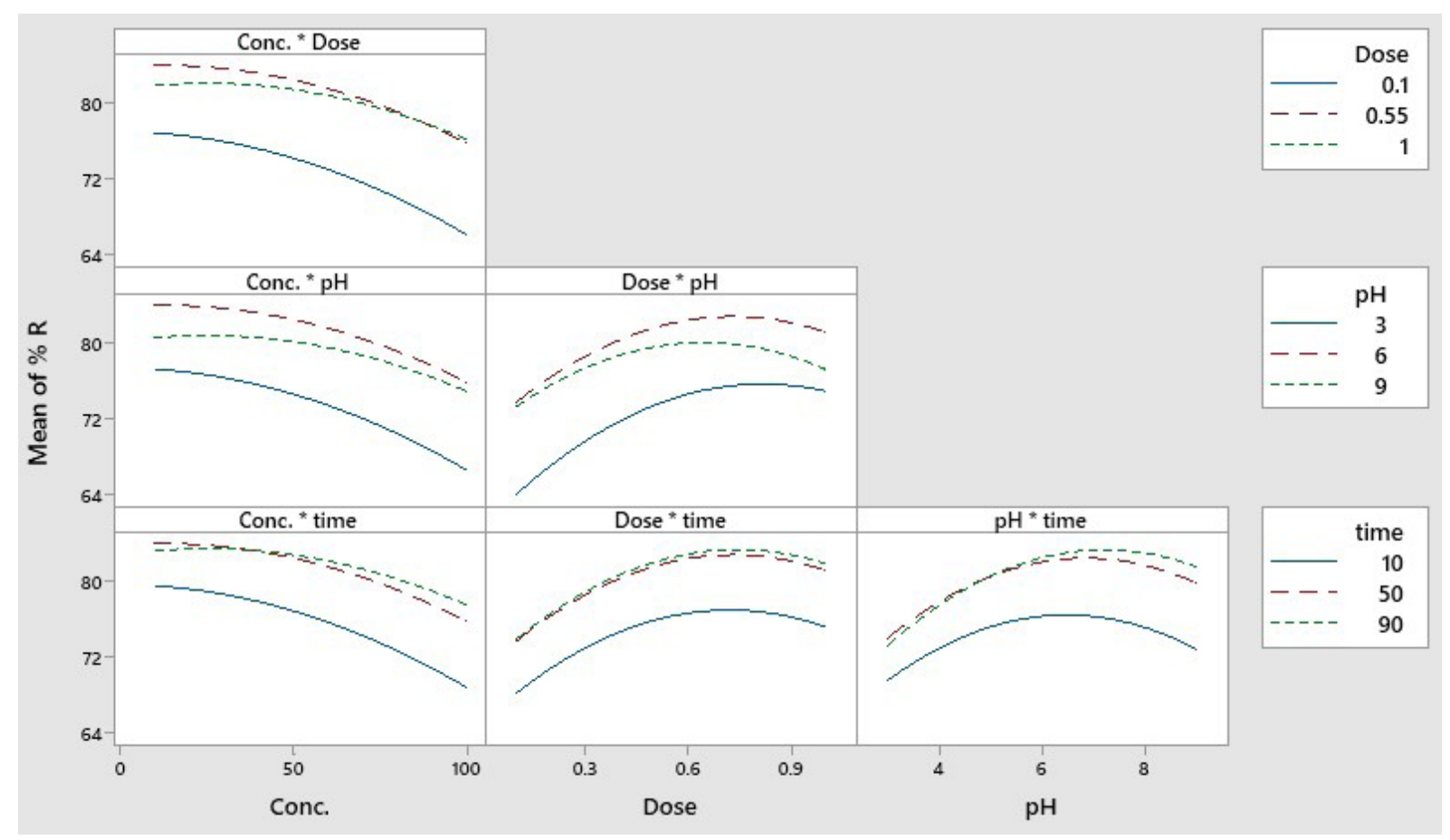

Figure 8. The interacting effect of operating factors 


\section{ADSORPTION ISOTHERMS}

There are many isotherm adsorption models describing the distribution of the adsorbate molecules in the liquid phase with the adsorbent in the solid phase at the equilibrium state. The most classical adsorption isotherm models are Langmuir and Freundlich that are used to show the homogeneity interacting between the adsorbate and adsorbent (Dakhil 2015a). The Langmuir model described the monolayer distribution of adsorbate ions in the liquid phase on the vacant sites of the adsorbent in the solid phase. The linear expression of the Langmuir model can be written in the following equation (4) (Dakhil 2015b, Jiang and $\mathrm{Hu} 2019)$ :

$$
\frac{1}{q_{e}}=\frac{1}{q_{o}}+\frac{1}{q_{o} K_{l}} \cdot \frac{1}{C_{e}}
$$

The equilibrium adsorption capacity at end of the experiment is represented by the symbol of $\mathrm{q}_{\mathrm{e}}\left(\mathrm{mg} \cdot \mathrm{g}^{-1}\right)$. The linear plot of $1 / \mathrm{q}_{\mathrm{e}}$ against $1 / \mathrm{C}_{\mathrm{e}}$ was used to examine the applicability of the equilibrium results of aniline adsorption by $\mathrm{MRH}$ as shown in Figure 9. The magnitude of Langmuir

Table 5. Constants of isotherm models

\begin{tabular}{|c|c|c|c|c|c|}
\hline \multicolumn{3}{|c|}{ Langmuir Constants } & \multicolumn{3}{c|}{ Freundlich Constants } \\
\hline $\mathrm{q}_{\circ}$ & $\mathrm{K}_{\mathrm{l}}$ & $\mathrm{R}^{2}$ & $\mathrm{~K}_{\mathrm{f}}$ & $\mathrm{n}$ & $\mathrm{R}^{2}$ \\
\hline 16.995 & 0.05125 & $98.9 \%$ & 1.2314 & 1.1795 & $98.7 \%$ \\
\hline
\end{tabular}

constants; $\mathrm{q}_{\mathrm{o}}$ and $\mathrm{K}_{1}$; can be determined by intercept and slope, respectively. The experimental results were confirmed by this model with a high value of correlation coefficient $\left(\mathrm{R}^{2}=98.9\right)$.

The empirical equation of the second model of adsorption isotherm; the Freundlich model; which describe the adsorption process in heterogeneous systems can be expressed in linear form as shown in equation (5) (He et al. 2021):

$$
\ln q_{e}=\ln K_{f}+\frac{1}{n} \ln C_{e}
$$

The value of Freundlich constants; $\mathrm{K}_{\mathrm{f}}$ and $\mathrm{n}$; can be determined from intercept and slope of linear plotting $\ln$ qe against $\ln \mathrm{Ce}$ as shown in Figure 10. The correlation coefficient of the experimental results was also well confirmed with the Freundlich model $\left(\mathrm{R}^{2}=98.7 \%\right)$. The values of Langmuir and Freundlich constants were illustrated in Table 5. The high values of correlation coefficient $\left(\mathrm{R}^{2}\right)$ for both models illustrate that the mathematical model fit and was in agreement with isotherm models. These results indicate the formation of a mono heterogeneous layer of aniline ions over the MRH adsorbent.

\section{CONCLUSIONS}

The ability of MRH for the efficient removal of aniline ions from simulated wastewater was proven. The influence of individual factors and

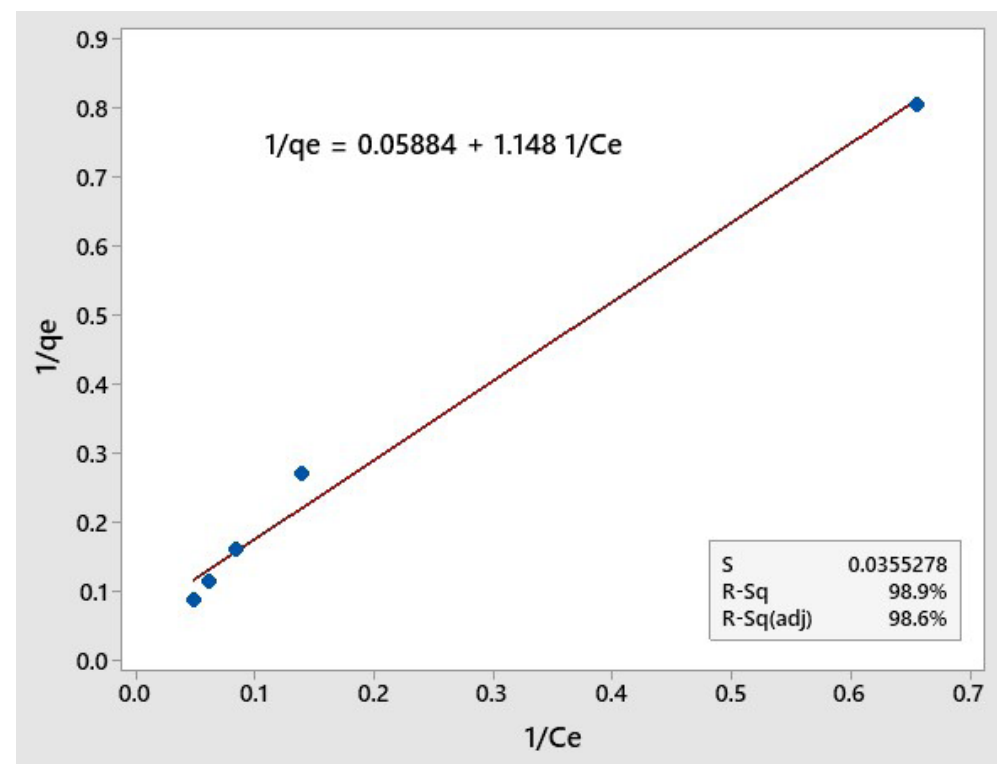

Figure 9. Langmuir isotherm model 


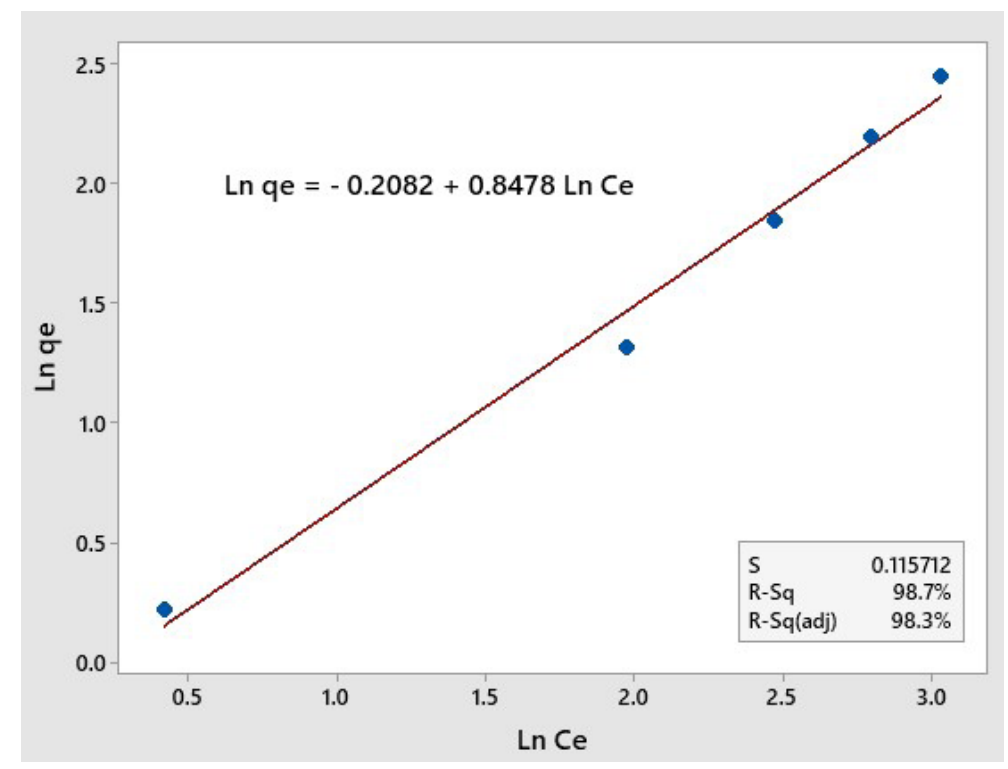

Figure 10. Freundlich isotherm model

interacting factors that control the adsorption process was studied. The highest removal efficiency of aniline was $84.97 \%$, which occurred at the optimum values of operating factors at 25 g.L. $\mathrm{L}^{-1}$ of the initial concentration of aniline, MRH dose $0.68 \mathrm{~g}, \mathrm{pH} 6.6$, and contact time $70 \mathrm{~min}$. The point of zero charge was found to equal 6.6. The equilibrium results fitted with the standard isotherm model were examined to prove consistency of the removal mathematical model.

\section{Acknowledgments}

The authors thank Al-Muthanna University for its continuous support to researchers, as well as the thanks to the College of Engineering/ Department of Chemical Engineering and the staff who are working in laboratories for providing technical support to accomplish this work.

\section{REFERENCES}

1. Ahmadi, S., F.K. Mostafapour, and E. Bazrafshan. 2017. Removal of aniline from aqueous solutions by coagulation/flocculation-flotation. Chem Sci Int J 1: 1-10.

2. Ahmed, H., G. Naser, and A. Alkaim. 2018. Treatment of Textile Industries Wastewater by Advance Oxidation Process. J. Eng Appl. Sci.: 1042-1045.

3. Ali, A.H. 2017. Preparation and Characterization of Nanoparticles TiO2 and Its Application for Methylene Blue Dye Degradation under Solar Light. Journal of Global Pharma Technology.
4. Ali, A.H., and I.H. Dakhil. 2012. Photocatalytic decolorization of Methyl Red dye under solar light. Jornal of kerbala university 10 .

5. Chang, Y.-P., C.-L. Ren, J.-C. Qu, and X.-G. Chen. 2012. Preparation and characterization of Fe3O4/ graphene nanocomposite and investigation of its adsorption performance for aniline and p-chloroaniline. Applied Surface Science 261: 504-509.

6. Dakhil, I.H. 2013. Adsorption of Chromium (VI) from Aqueous Solutions using Low Cost Adsorbent: Equilibrium and Regeneration Studies. Journal of Engineering 19: 1395-1407.

7. Dakhil, I.H. 2015a. Adsorption of Lead from Industrial Effluents using Rice Husk. International Journal of Engineering and Management Research (IJEMR) 5: 109-116.

8. Dakhil, I.H. 2015b. Effect of Adding Zinc Oxide on Waste Rubber Tire Powder for Increasing Adsorption of Cadmium (II) from Wastewater. The Iraqi Journal For Mechanical And Material Engineering: 416-427.

9. Dakhil, I.H. 2016a. Acomparative Study for Removal of Dyes from Textile Effluents by Low Cost Adsorbents. Mesop. environ. j, Spicial Issue A:1-9.

10. Dakhil, I.H. 2020. Recycling of Agriculture Wastes for Efficient Removal of Methyl Orange Dye Using Batch Adsorption Unit. Page 012186 in IOP Conference Series: Materials Science and Engineering. IOP Publishing.

11. Dakhil, I.H., and A.H. Ali. 2021. Adsorption of methylene blue dye from industrial wastewater using activated carbon prepared from agriculture wastes. Desalination and Water Treatment 216: 372-378.

12. Dakhil, I.H., G.F. Naser, and A.H. Ali. 2021. Response Surface Modeling of Arsenic Adsorption by 
Modified Spent Tea Leaves. Page 012129 in IOP Conference Series: Materials Science and Engineering. IOP Publishing.

13. Dakhil, L.I.H. 2016b. Removal of Kerosene from Wastewater Using Locally Sawdust. Page 17 in Proceeding of 1st International Conference of Southern Technical University/Iraq.

14. Ferreira, M., M. Pinto, I.C. Neves, A. Fonseca, O. Soares, J. Órfão, M. Pereira, J. Figueiredo, and P. Parpot. 2015. Electrochemical oxidation of aniline at mono and bimetallic electrocatalysts supported on carbon nanotubes. Chemical Engineering Journal 260: 309-315.

15. He, S., G. Chen, H. Xiao, G. Shi, C. Ruan, Y. Ma, H. Dai, B. Yuan, X. Chen, and X. Yang. 2021. Facile preparation of $\mathrm{N}$-doped activated carbon produced from rice husk for $\mathrm{CO} 2$ capture. Journal of colloid and interface science 582: 90-101.

16. Jiang, Y., H. Wang, Y. Shang, and K. Yang. 2016. Simultaneous removal of aniline, nitrogen and phosphorus in aniline-containing wastewater treatment by using sequencing batch reactor. Bioresour Technol 207: 422-429.

17. Jiang, Z., and D. Hu. 2019. Molecular mechanism of anionic dyes adsorption on cationized rice husk cellulose from agricultural wastes. Journal of Molecular Liquids 276: 105-114.

18. Khaniabadi, Y.O., R. Heydari, H. Nourmoradi, H. Basiri, and H. Basiri. 2016. Low-cost sorbent for the removal of aniline and methyl orange from liquid-phase: aloe vera leaves wastes. Journal of the Taiwan institute of chemical engineers 68: 90-98.

19. Kolar, P., and H. Jin. 2019. Baseline characterization data for raw rice husk. Data in brief 25:104219.

20. Liu, Q., L. Zhang, P. Hu, and R. Huang. 2015. Removal of aniline from aqueous solutions by activated carbon coated by chitosan. Journal of Water Reuse and Desalination 5: 610-618.
21. Melliti, A., V. Srivastava, J. Kheriji, M. Sillanpää, and B. Hamrouni. 2021. Date Palm Fiber as a novel precursor for porous activated carbon: Optimization, characterization and its application as Tylosin antibiotic scavenger from aqueous solution. Surfaces and Interfaces 24: 101047.

22. N'Diaye, A., C. Boudokhane, M. Kankou, and H. Dhaouadi. 2019. Potential of rice husk ash in atrazine removal. Chemistry and Ecology 35: 678-692.

23. Shao, L., X.Q. Cheng, Y. Liu, S. Quan, J. Ma, S. Z. Zhao, and K.Y. Wang. 2013. Newly developed nanofiltration (NF) composite membranes by interfacial polymerization for Safranin O and Aniline blue removal. Journal of Membrane Science 430: 96-105.

24. Srivastava, V.C., I.D. Mall, and I.M. Mishra. 2006. Characterization of mesoporous rice husk ash (RHA) and adsorption kinetics of metal ions from aqueous solution onto RHA. Journal of hazardous materials 134: 257-267.

25. Taher, I.A., I. Dakhil, Z. Kubba, and A.H. Ali. 2018. Degradation High Concentration of Eosin Yellowish Dye in Heterogeneous Catalyst Solution. Journal of Global Pharma Technology 10: 704-709.

26. Thakur, S., and K. Qanungo. 2020. Removal of aniline blue from aqueous solution using adsorption: A mini review. Materials Today: Proceedings.

27. Zhou, Y., X. Gu, R. Zhang, and J. Lu. 2014. Removal of aniline from aqueous solution using pine sawdust modified with citric acid and $\beta$-cyclodextrin. Industrial \& Engineering Chemistry Research 53: 887-894.

28. Zhou, Y., R. Zhang, K. Chen, X. Zhao, X. Gu, and J. Lu. 2017. Enhanced adsorption and photo-degradation of bisphenol A by $\beta$-cyclodextrin modified pine sawdust in an aquatic environment. Journal of the Taiwan institute of chemical engineers 78: 510-516. 